\title{
SLENDER PROFILES FOR MOMENT RESISTING FRAMES IN MODERATE SEISMICITY REGIONS - NUMERICAL AND EXPERIMENTAL INVESTIGATIONS -
}

\author{
Matthias Wieschollek $^{1}$, Benno Hoffmeister ${ }^{1}$ and Markus Feldmann ${ }^{1}$ \\ ${ }^{1}$ RWTH Aachen University \\ Institute of Steel Construction \\ 52074 Aachen, Germany \\ wieschollek@stb.rwth-aachen.de
}

Keywords: Earthquake Engineering, Moment Resisting Frames, Welded and bolted Connections, Cyclic Behaviour of Slender Profiles, Seismic Design, Behaviour factor.

\begin{abstract}
Moment resisting steel frames offer an excellent ductility and energy dissipation and can be designed using high behaviour factors. The condition however is, that compact cross-sections are used allowing for large rotations in the plastic hinges. Portal frames, as commonly designed and built for storage or industrial applications, are usually aiming at light weight solutions in order to be competitive to prefabricated concrete halls. Class 3 or 4 profiles are preferably used, this prevents however the application of any significant behavior factor. In particular in low and moderate seismicity regions a behaviour factor in the range of 2-3 would be fully sufficient in order to achieve an economically optimum design.
\end{abstract}

The aim of the investigations presented in this paper is the determination of the cyclic performance of knee joints made of slender steel-sections. Four different slender joint types are investigated numerically and experimentally and compared to the performance of a compactsection joint. The definition of the test setup and testing procedure is done using a "virtualpush-over" FE-analysis. This analysis is used to define the amplitudes of test cycles as well as the expected forces and deformations. By applying expected material properties also the cyclic tests are predicted allowing for an assessment of the expected damage and an optimum placement of measuring devices. Using the actual, measured dimensions and material properties of the test specimens a more refined calculation of the expected performance is obtained. The experimental tests are performed under cyclic loading only as the static push-over results are available from the numerical simulations. The cyclic tests provide the measured data of global and local deformations and strains, which are essential for the verification of the local buckling phenomena in slender cross-sections under cyclic actions. These results are used for a fine-tuning of the numerical models regarding imperfections and material properties. Knowing the influence and the range of parameter obtained from tests it is possible to extend the numerical simulations to other geometries and to complete frames under realistic seismic actions. 


\section{INTRODUCTION}

As part of the European Research Project MEAKADO "Design of steel and composite structures with limited ductility requirements for optimized performances in moderate earthquake areas" the cyclic behaviour of slender profiles for moment resting frames (MRF) in moderate seismicity regions are currently being researched. The experimental and numerical investigations are described in detail within the Deliverables D2.1a [1] and D2.2 [2]. By analogy with [3] this paper summarize the results for the investigated frame corners made of slender steel cross sections. The motivation for this research was particularly the fact that according to the current version of Eurocode 8 [4] only cross-sectional classes 1 or 2 are permitted for steel or composite structures when a considerable behaviour factor is intended to be taken into account. Within MRF's almost all members are affected by this limitation:

- Single-bay - single-storey steel frames: Such structures are part of a highly competitive marked requiring a strong optimisation in terms of material requirement and ease of construction. Light weight steel frames are an optimum solution so far, with the exception of seismic regions where the above mentioned restrictions strongly limit their applicability despite their low masses.

- Multi-bay - multi-storey composite buildings: Due to the high position of neutral axis of composite cross-sections in negative bending the web of steel profiles is very often to be classified as class 3 or 4 section, although almost all rolled steel profiles may be classified as class 1 or 2 cross-sections.

The above mentioned aspects are of particular importance in countries with moderate seismicity regions, where a special adoption of the otherwise common types of structures presents a great obstacle for the small and medium size companies active in this market. Hence an extension of the applicability of the afore mentioned structural types to moderate seismic regions would largely enhance their competitiveness. This leads to the following objectives:

- Extension of the applicability of class 3 or 4 steel cross sections within single-bay single-storey frames to moderate seismic actions by means of characterization of class 4 cross sections in terms of rotational behaviour and energy dissipation.

- Extension of the applicability of class 3 (web) composite sections to moderate seismic actions by means of characterization of class 3 composite cross section in terms of rotational behaviour and energy dissipation.

- Identification and definition of $b / t$ values rather than cross-sectional classes to be limited depending on the targeted energy dissipation and the corresponding deformations by means of numerical analyses.

\section{EXPERIMENTAL TEST ON FRAME CORNERS}

\subsection{Generals}

The test program considered typical welded profiles typically used for light weight frames of small industrial or storage halls. In total 6 cyclic tests on frame corners with welded and bolted connections as well as haunched and constant depth girders were carried out. The test specimens were designed such that for constant depth girders the plastic hinges developed in the beams whereas for the haunched girders the plastic hinges developed in the top of the column. The tests were performed according to the ECCS testing procedure [5] with increasing amplitudes of deformation cycles and were executed until collapse (e.g. rupture due to low cycle fatigue or extensive local buckling). The measurements were evaluated with regard to the development of the hysteretic behaviour with particular emphasis on the degradation. 


\subsection{Description of test specimens}

The 6 specimens have been manufactured in collaboration with the company OCAM in Italy. Each type of material used for the test specimens has been taken from a single steel charge, whereby plates with equal plate thicknesses were made of the same production batch. In order to have accurate material characteristics for the numerical simulations of the tests and especially for the determination of the test procedure for cyclic loading, some small scale specimens were taken from the material of the specimens. These small scale specimens were tested under monotonic loading. Table 1 summarizes the test results and Figure 1 shows the stress-true strain curves obtained from the tests together with the stress-strain curves extrapolated according to Hollomon [6] which were applied for the monotonic simulations.

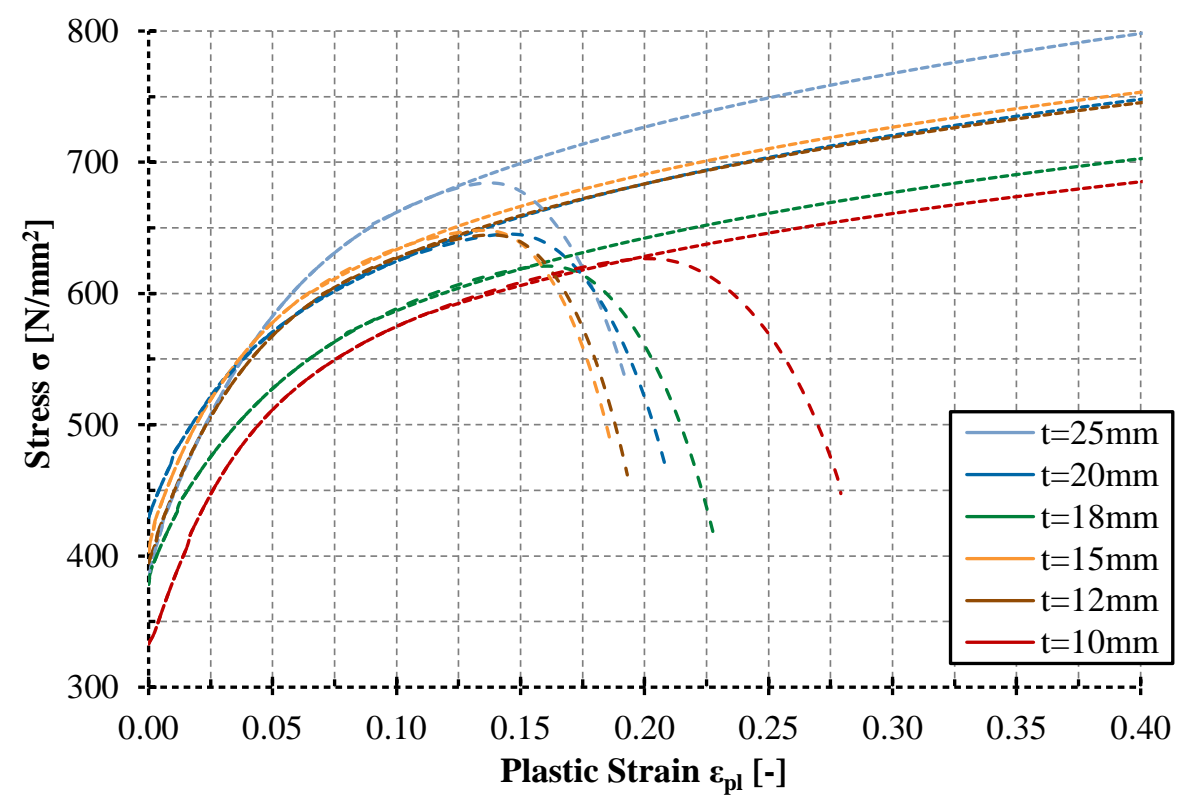

Figure 1: True and extrapolated stress-strain curves

\begin{tabular}{ccccccc}
\hline $\begin{array}{c}\text { Plate thickness } \\
\mathbf{t}[\mathbf{m m}]\end{array}$ & $\mathbf{2 5 . 0}$ & $\mathbf{2 0 . 0}$ & $\mathbf{1 8 . 0}$ & $\mathbf{1 5 . 0}$ & $\mathbf{1 2 . 0}$ & $\mathbf{1 0 . 0}$ \\
\hline \hline Steel grade & $\mathrm{S} 355 \mathrm{~J} 2+\mathrm{N}$ & $\mathrm{S} 355 \mathrm{~J} 2+\mathrm{N}$ & $\mathrm{S} 355 \mathrm{~J} 2+\mathrm{N}$ & $\mathrm{S} 355 \mathrm{~J} 2+\mathrm{N}$ & $\mathrm{S} 355 \mathrm{~J} 2+\mathrm{N}$ & $\mathrm{S} 355 \mathrm{~J} 2+\mathrm{N}$ \\
$f_{y}[\mathrm{MPa}]$ & 376 & 420 & 372 & 385 & 389 & 331 \\
$f_{u}[\mathrm{MPa}]$ & 595 & 553 & 527 & 562 & 562 & 521 \\
$f_{y} / f_{u}[-]$ & 0.63 & 0.76 & 0.71 & 0.68 & 0.69 & 0.64 \\
$\varepsilon_{u}[\%]$ & 24.6 & 30.0 & 31.2 & 31.0 & 31.5 & 35.7 \\
\hline
\end{tabular}

Table 1: Material characteristics obtained from small scale tests

Different examples for MRF's have been compiled from literature as well as from direct dialogue with manufacturers to mirror the state-of-the-art. Following these examples the geometries, plate thicknesses and joint details have been assigned. Furthermore it has been decided to test only frame corners as subsystems of a complete MRF and due to the test setup the length of the beams and columns were limited. All specimens were made as class 3 cross sections and in order to reach plastic hinges in the beams and columns the panel zones were reinforced, whereby one additional test on a frame corner without a reinforcement and one additional test on a frame corner made of class 1 cross sections with comparable monotonic resistance and stiffness were carried out. The 6 different specimens that was decided on were: 
- S1 - Welded frame corner with constant girder

- S2 - Bolted frame corner with constant girder

- S3 - Welded frame corner with haunched girder

- S4 - Bolted frame corner with haunched girder

- S5 - Welded frame corner with constant girder - class 1

- S6 - Welded frame corner with constant girder - unreinforced panel zone

Figure 2 shows the above mentioned specimens or types of frame corners respectively, while Figure 3 illustrates the principle geometry of the test specimens. The main dimensions (e.g. length of column and beam, cross-sectional height and width) were equal for all specimens. After delivery all test specimens have been investigated with regard to tolerances that may influence the test results. Table 2 gives the results of the measured dimensions that have been taken according to the measurement scheme as shown in Figure 3.

The final step to prepare the specimens for the tests was the application of strain gauges at the (numerically predicted) critical positions, but also on undisturbed areas of the beams and columns. These strain gauge applications on the one hand allowed to detect a damage initiation during the tests as well as on the other hand enabled to calibrate and verify the numerical finite element models.
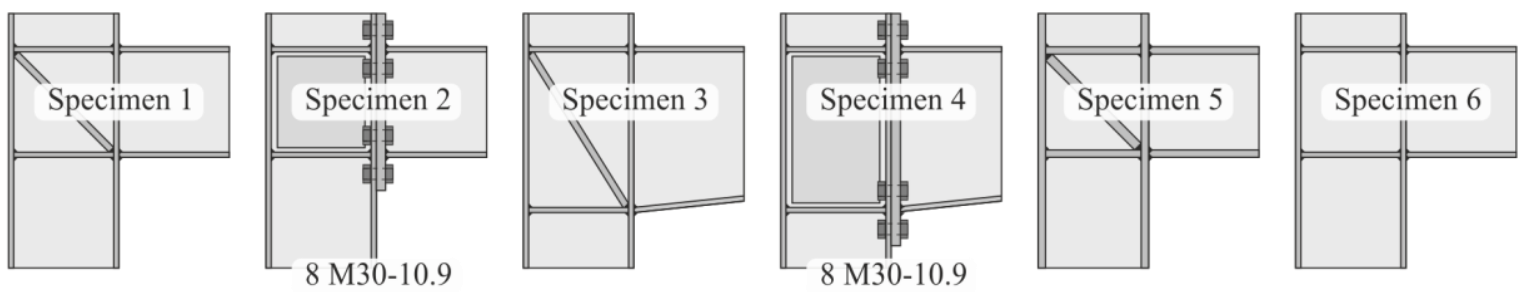

Figure 2: Overview of the specimens - types of frame corners

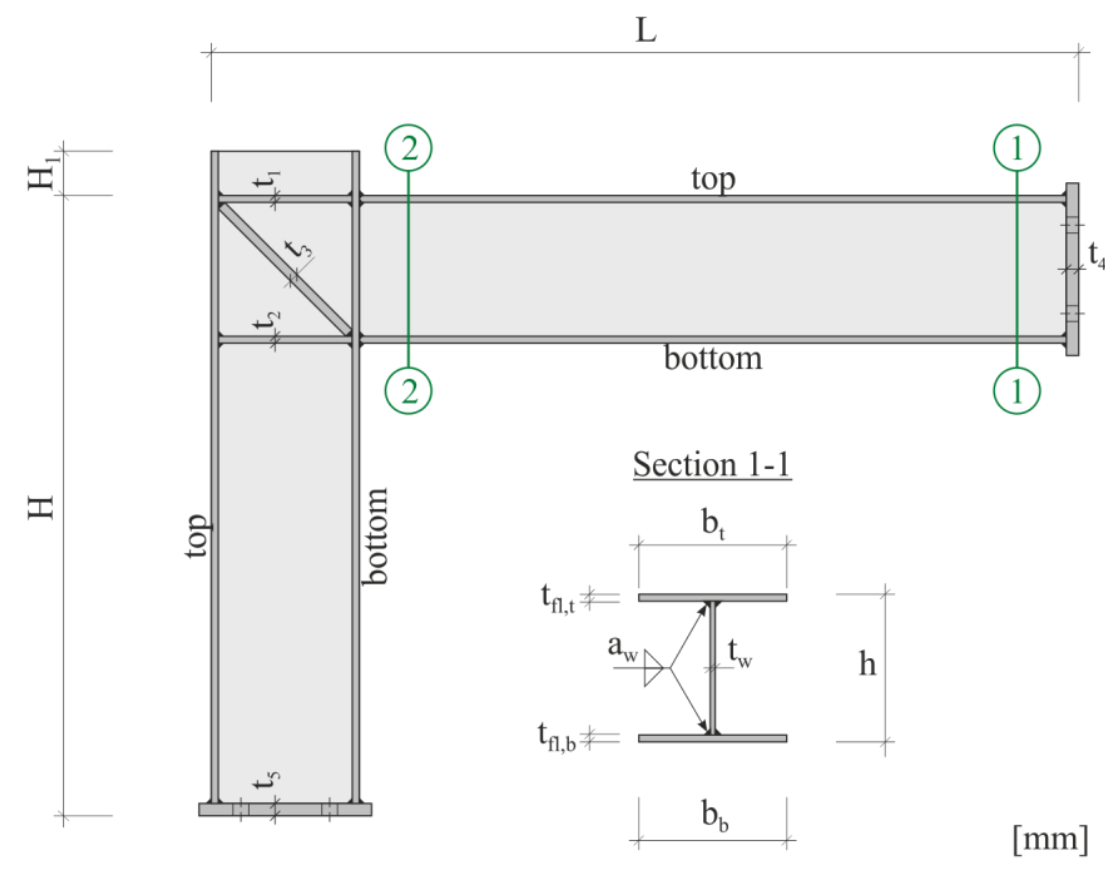

Figure 3: Overview of specimen dimensions using specimen S1 


\begin{tabular}{|c|c|c|c|c|c|c|c|c|c|c|c|c|}
\hline \multirow{2}{*}{\multicolumn{2}{|c|}{ Specimen }} & \multirow[t]{2}{*}{$L$} & \multirow{2}{*}{$h_{1}$} & \multirow{2}{*}{$\overline{h_{2}}$} & \multirow{2}{*}{$\begin{array}{c}b \\
{[\mathrm{~mm}]}\end{array}$} & \multirow[t]{2}{*}{$t_{f l}$} & \multirow[t]{2}{*}{$t_{w}$} & \multirow[t]{2}{*}{$a_{w}$} & \multicolumn{2}{|c|}{ Web } & \multicolumn{2}{|c|}{ Flange } \\
\hline & & & & & & & & & $\mathrm{c} / \mathrm{t}$ & Class & $\mathrm{c} / \mathrm{t}$ & Class \\
\hline S1 & \multirow{6}{*}{ 矛 } & 1772 & 296 & 296 & 300 & 15.3 & 10.0 & 6.0 & 24.9 & 1 & 9.0 & 3 \\
\hline $\mathrm{S} 2$ & & 1760 & 296 & 296 & 300 & 15.5 & 10.0 & 6.0 & 24.8 & 1 & 8.8 & 3 \\
\hline S3 & & 1760 & 303 & 442 & 300 & 15.4 & 10.0 & 6.0 & 39.4 & 1 & 8.9 & 3 \\
\hline S4 & & 1760 & 304 & 446 & 300 & 15.5 & 10.0 & 6.0 & 39.8 & 1 & 8.8 & 3 \\
\hline S5 & & 1760 & 298 & 298 & 250 & 18.6 & 10.0 & 6.0 & 24.4 & 1 & 6.0 & 1 \\
\hline \multirow[t]{2}{*}{ S6 } & & 1760 & 299 & 299 & 300 & 15.5 & 10.0 & 6.0 & 25.1 & 1 & 8.8 & 3 \\
\hline & & $H$ & $\mathrm{H}_{1}$ & $h$ & $\bar{b}$ & $t_{f l}$ & $t_{w}$ & $a_{w}$ & $\mathrm{c} / \mathrm{t}$ & Class & $c / t$ & Class \\
\hline $\mathrm{S} 1$ & \multirow{6}{*}{ 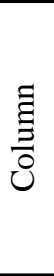 } & 1268 & 90 & 300 & 300 & 15.3 & 12.0 & 7.0 & 20.8 & 1 & 8.8 & 3 \\
\hline $\mathrm{S} 2$ & & 1260 & 90 & 297 & 300 & 15.2 & 12.0 & 7.0 & 20.6 & 1 & 8.8 & 3 \\
\hline S3 & & 1260 & 90 & 300 & 300 & 15.4 & 12.0 & 7.0 & 20.8 & 1 & 8.7 & 3 \\
\hline $\mathrm{S} 4$ & & 1260 & 88 & 300 & 300 & 15.3 & 12.1 & 7.0 & 20.6 & 1 & 8.8 & 3 \\
\hline S5 & & 1260 & 90 & 299 & 250 & 18.8 & 12.1 & 7.0 & 20.0 & 1 & 5.8 & 1 \\
\hline \multirow[t]{2}{*}{ S6 } & & 1260 & 90 & 300 & 300 & 15.5 & 12.0 & 7.0 & 20.8 & 1 & 8.7 & 3 \\
\hline & & $t_{1}$ & $t_{2}$ & $t_{3}$ & $t_{4}$ & $t_{5}$ & & & & & & \\
\hline S1 & \multirow{6}{*}{$\frac{\tilde{E}}{a}$} & 15.2 & 15.0 & 18.8 & 25.2 & 25.2 & & & & & & \\
\hline $\mathrm{S} 2$ & & 15.4 & 15.4 & $2 \times 12.0$ & 25.0 & 25.0 & & & & & & \\
\hline $\mathrm{S} 3$ & & 15.3 & 15.4 & 18.7 & 25.1 & 25.2 & & & & & & \\
\hline S4 & & 15.3 & 15.3 & $2 \times 12.0$ & 25.0 & 25.1 & & & & & & \\
\hline S5 & & 18.7 & 18.6 & 21.2 & 25.2 & 25.2 & & & & & & \\
\hline S6 & & 15.1 & 15.3 & - & 25.3 & 25.2 & & & & & & \\
\hline
\end{tabular}

Table 2: Actual measured values of the specimen dimensions

\subsection{Description of test setup}

The boundary conditions of the test setup have been particularly focused on a best possible representation of the real load-deformation behaviour of a complete MRF. The test setup is shown schematically in Figure 4, whereas the final realization with a test specimen can be seen in Figure 5.

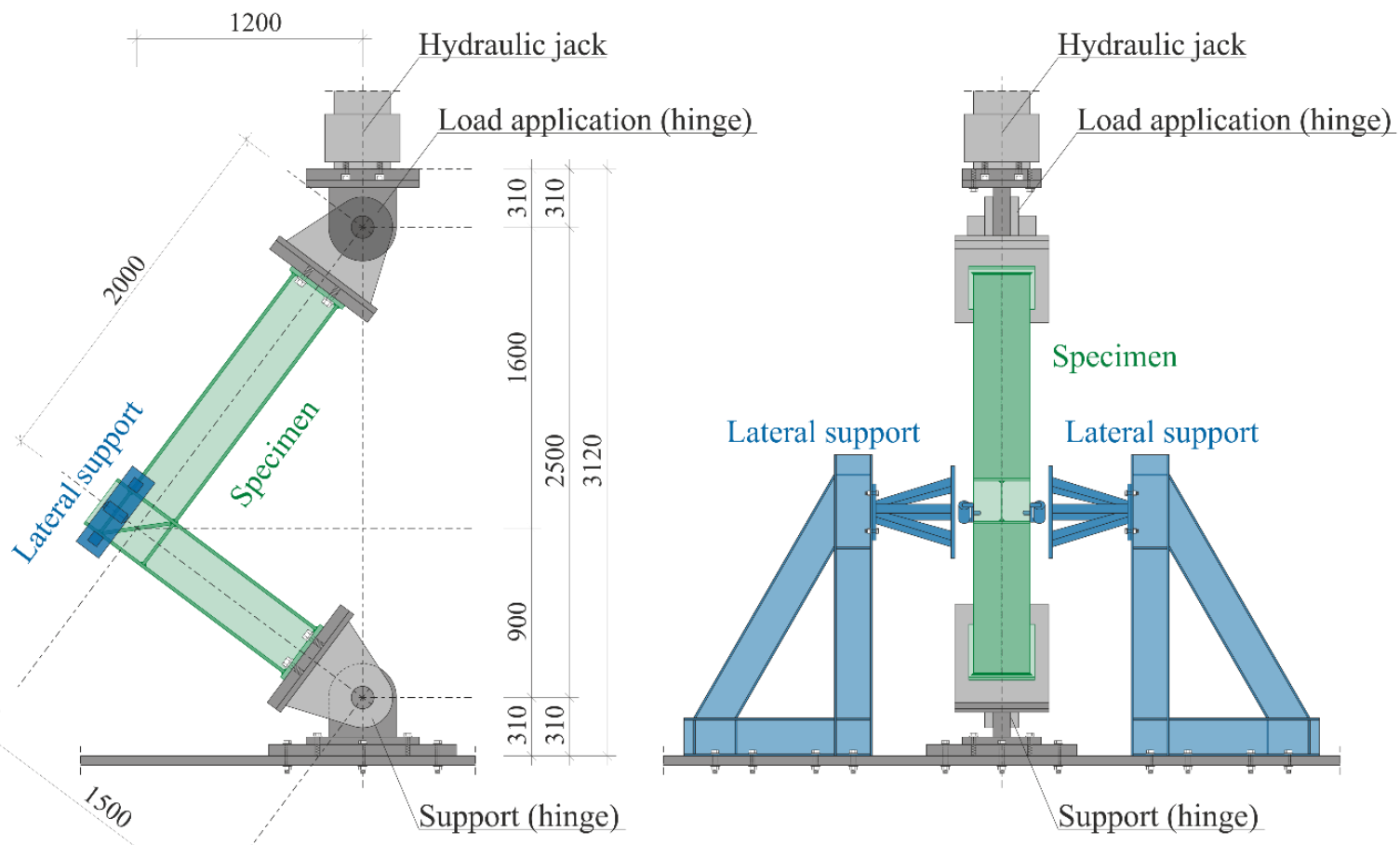

Figure 4: Schematic representation of the test setup 

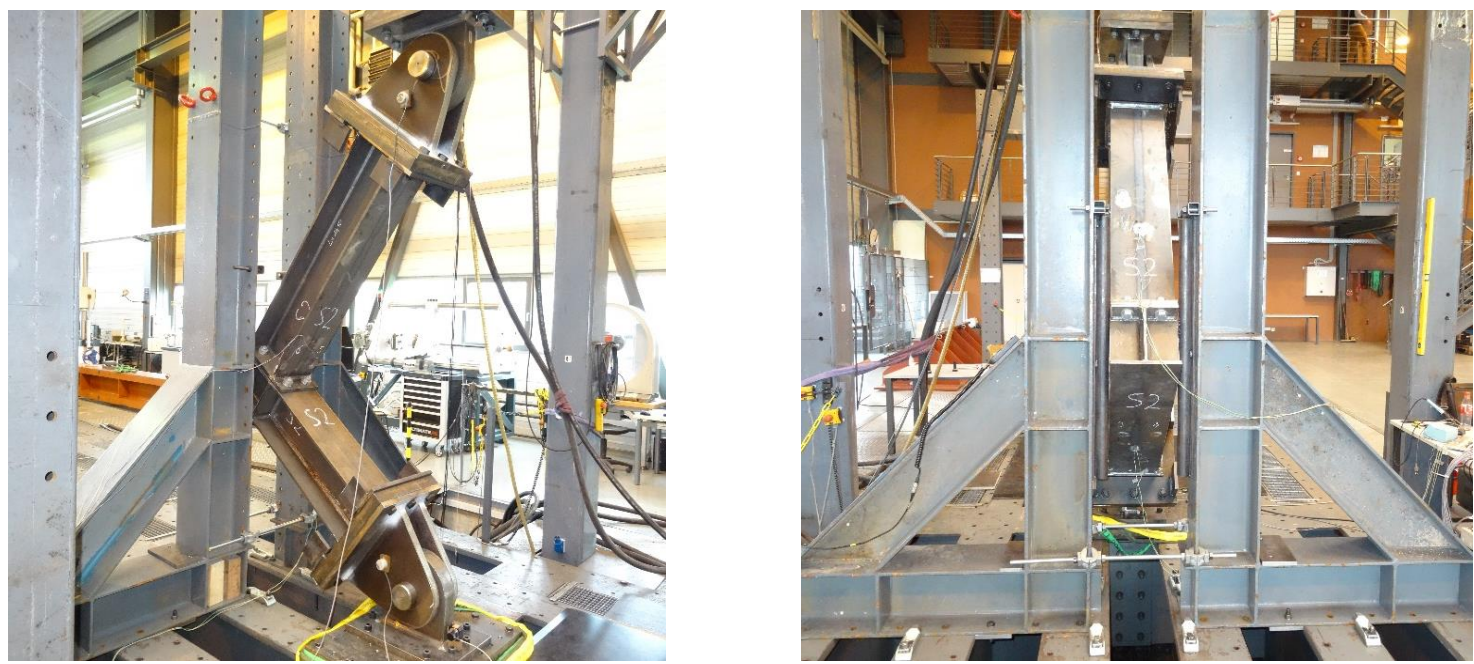

Figure 5: Test setup with test specimen S2

\section{$2.4 \quad$ Test procedure for cyclic loading}

According to the ECCS testing procedure [5] monotonic tests are required to define the test procedure for cyclic testing. Instead of these monotonic tests, here numerical simulations were used. Since the displacement $e_{y}$ corresponding to the yield load $F y$ were similar for tension and compression range, the average values were taken for the cyclic tests (Table 4). The loading history was applied as given schematically in Figure 6 and Table 3. Thereby the loading history was modified such that by refined gradation of the displacement amplitudes $e_{i}$ until failure the resolution of cyclic results has been increased.

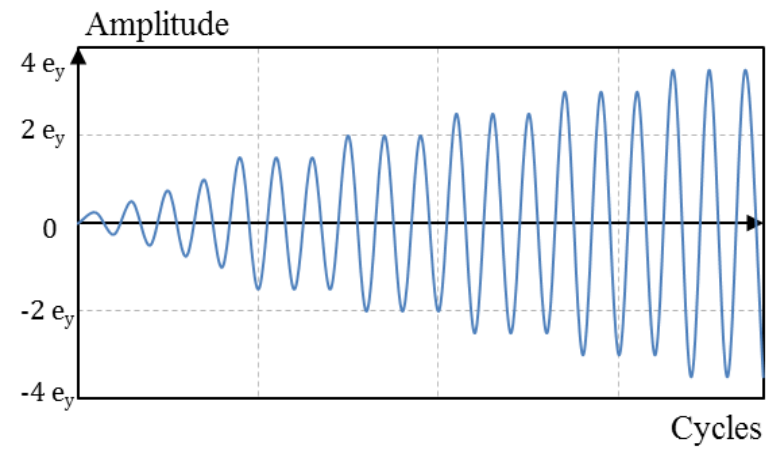

Figure 6: Schematic representation of the modified loading history according to ECCS [5]

\begin{tabular}{ccccccccc}
\hline Cycle & $\mathbf{1}$ & $\mathbf{2}$ & $\mathbf{3}$ & $\mathbf{4}$ & $\mathbf{5 - 7}$ & $\mathbf{8 - 1 0}$ & $\mathbf{1 1 - 1 3}$ & $\ldots$ \\
\hline \hline$e_{i}[\mathrm{~mm}]$ & $0.25 e_{y}$ & $0.5 e_{y}$ & $0.75 e_{y}$ & $e_{y}$ & $1.5 e_{y}$ & $2.0 e_{y}$ & $2.5 e_{y}$ & $\ldots$ \\
\hline
\end{tabular}

Table 3: Amplitudes of displacement for cyclic loading

\begin{tabular}{ccccccc}
\hline Specimen & S1 & S2 & S3 & S4 & S5 & S6 \\
\hline \hline$e_{y}[\mathrm{~mm}]$ & 24.0 & 24.0 & 20.0 & 20.0 & 24.0 & 16.0 \\
\hline
\end{tabular}

Table 4: Reference amplitudes of displacement for cyclic loading

\subsection{Test results for cyclic loading}

The test results in terms of cyclic load-displacement curves referring to the point of load application and pictures of the specimens at the end of the loading history showing the different failure modes of each specimen are shown in Figure 7 to Figure 12. 

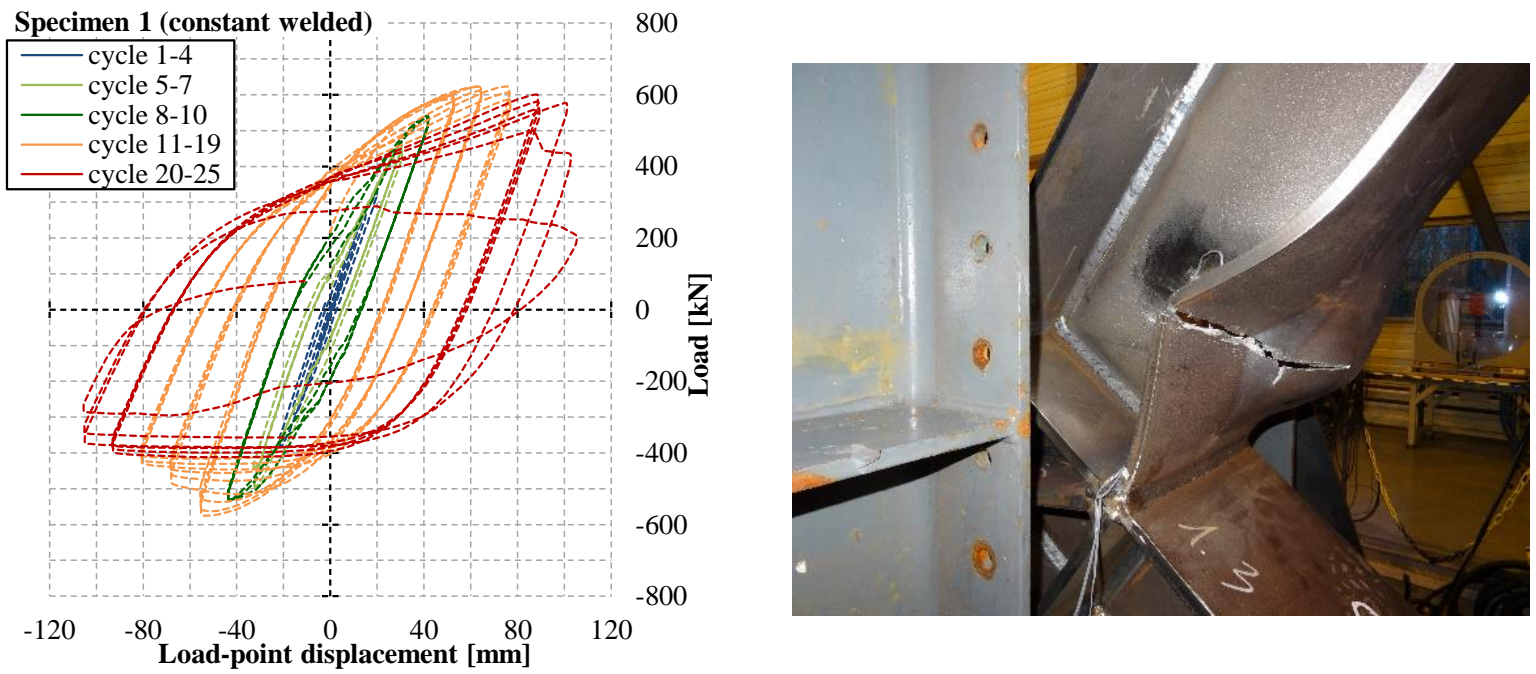

Figure 7: S1 - Cyclic load-displacement curve and failure mode
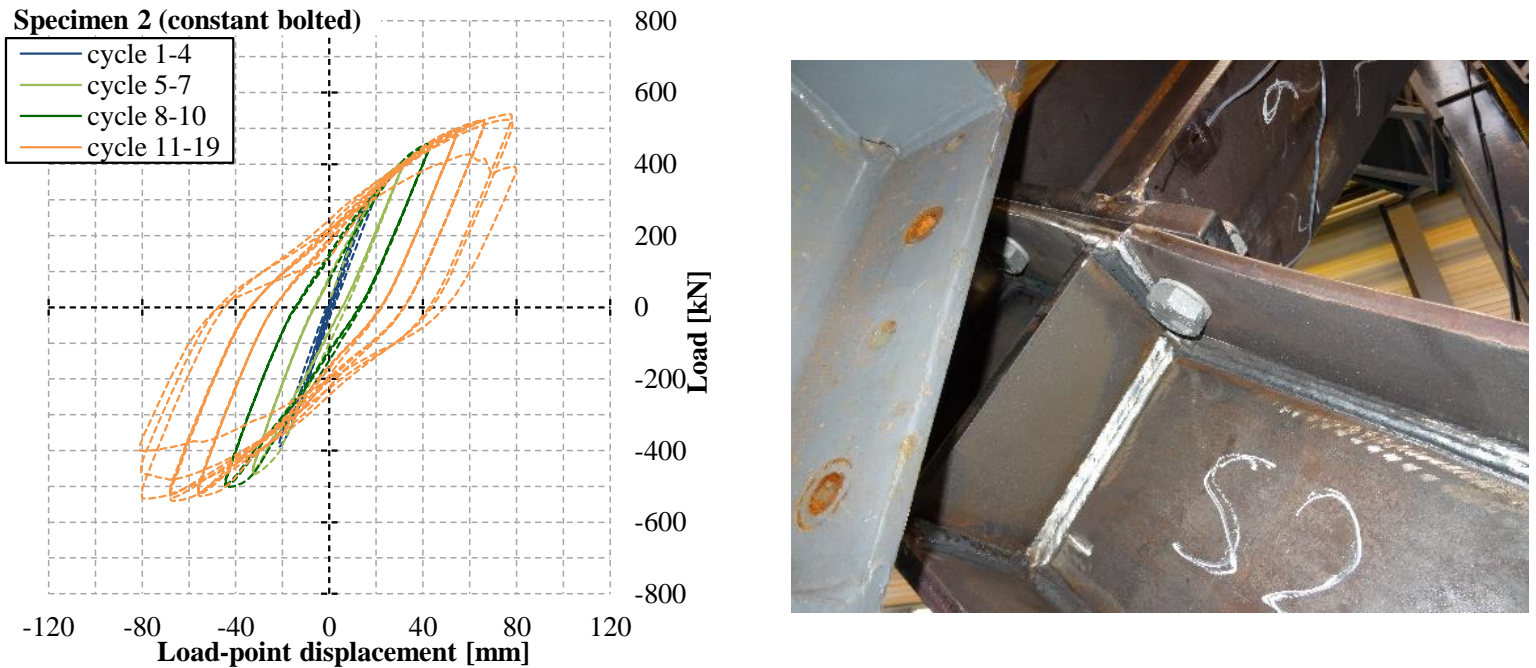

Figure 8: S2 - Cyclic load-displacement curve and failure mode
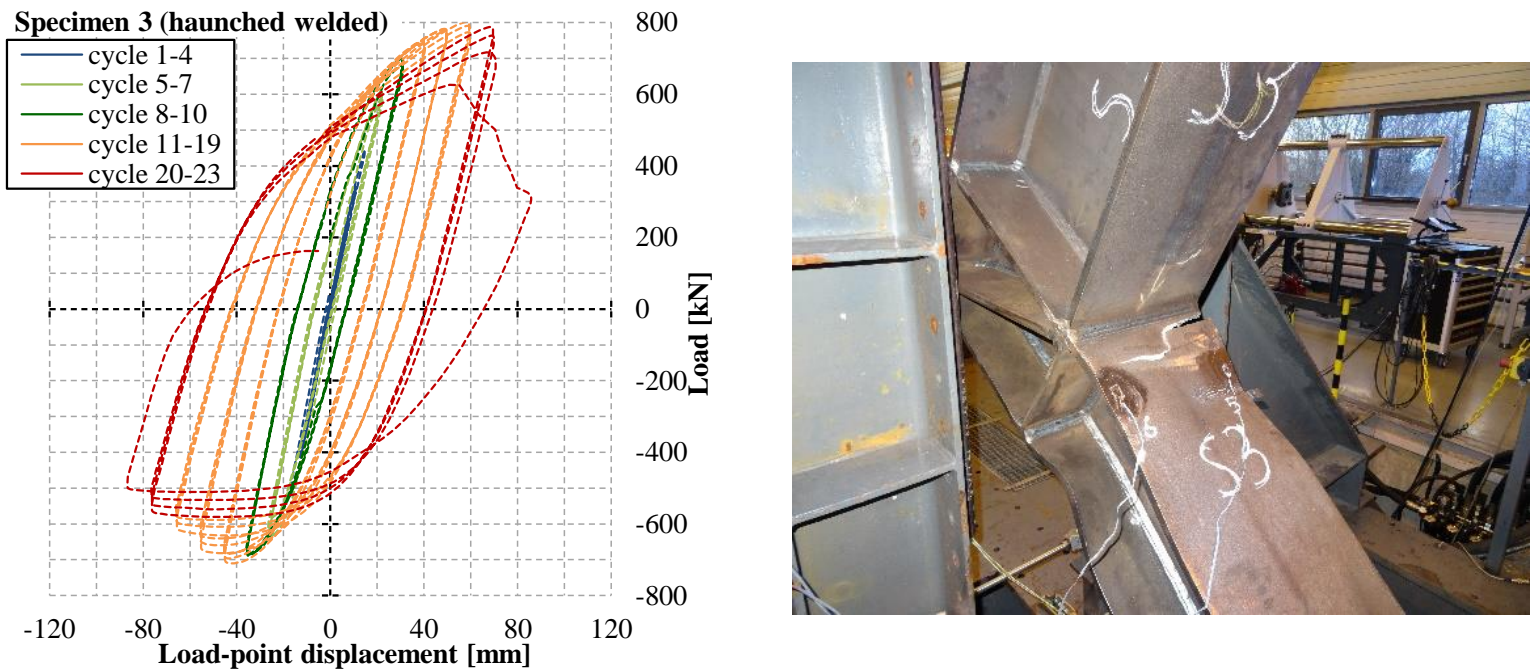

Figure 9: S3 - Cyclic load-displacement curve and failure mode 

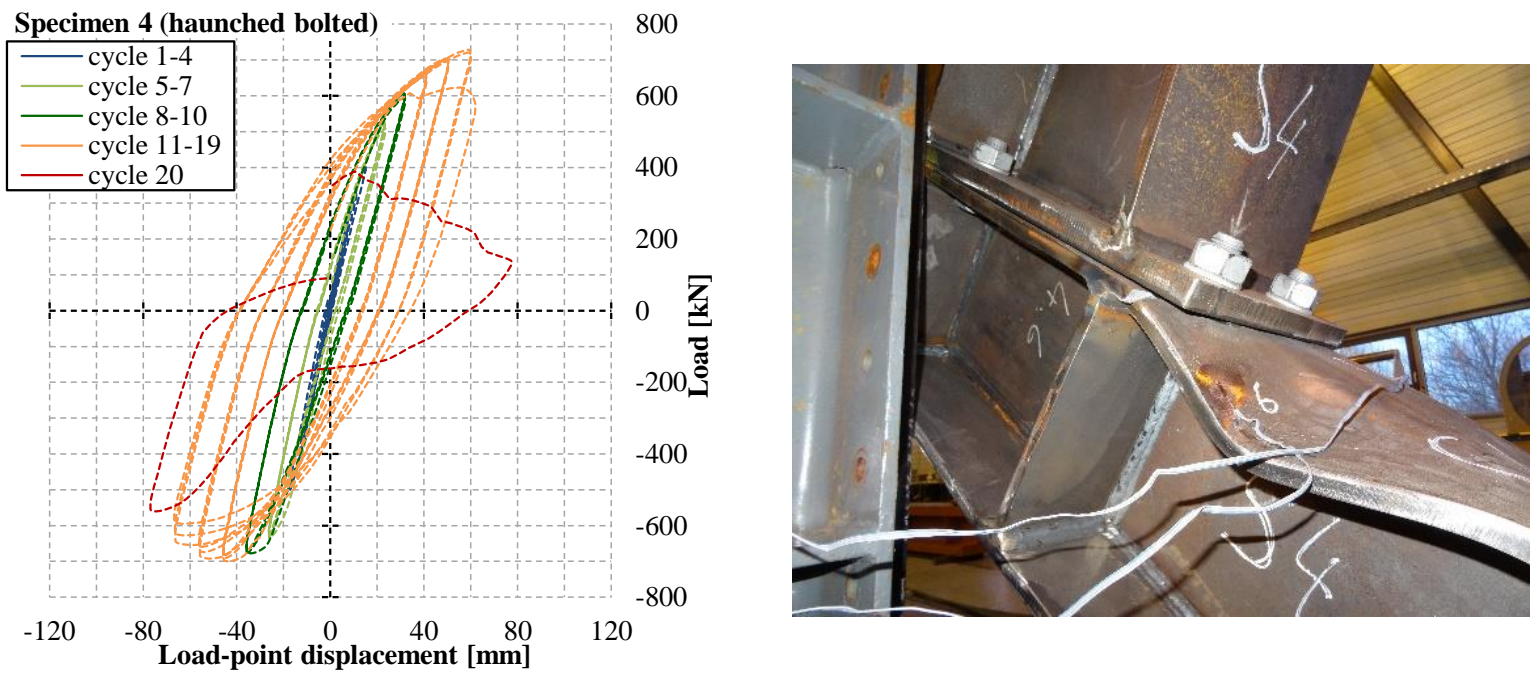

Figure 10: S4 - Cyclic load-displacement curve and failure mode
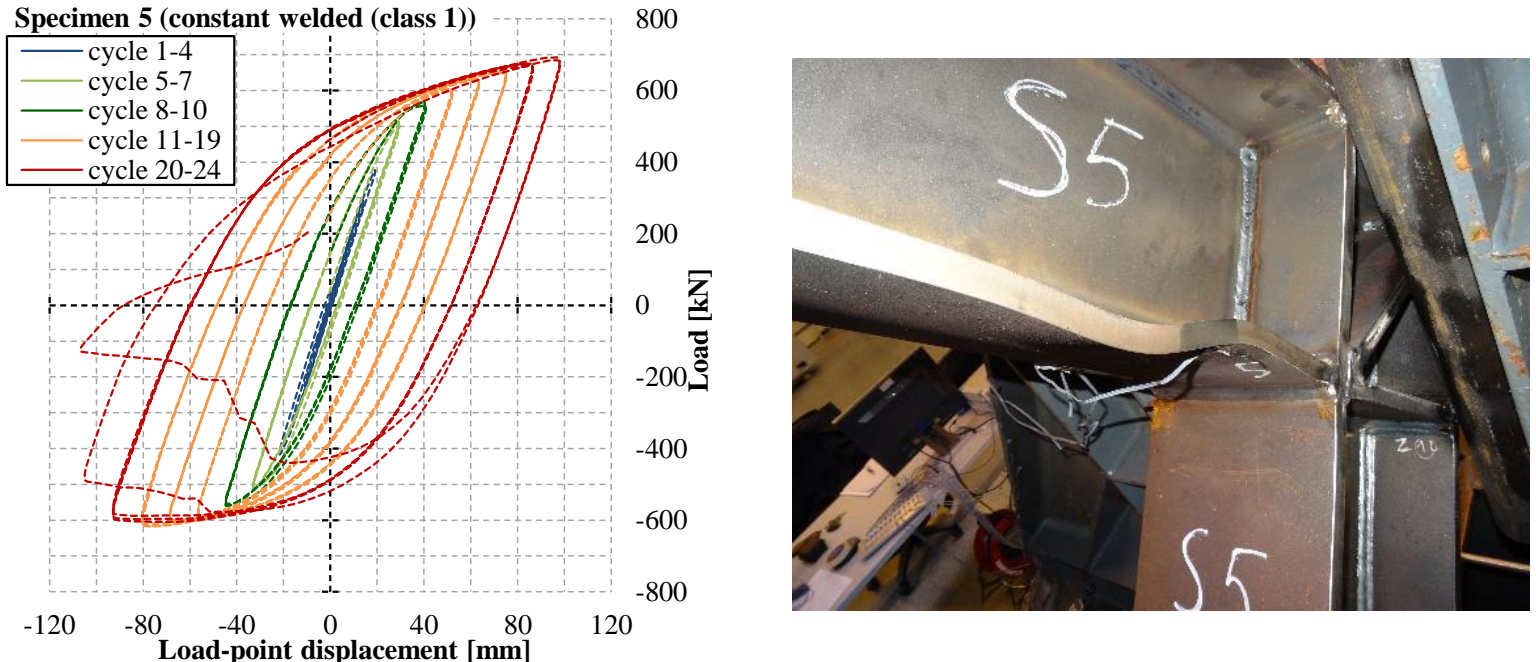

Figure 11: S5 - Cyclic load-displacement curve and failure mode
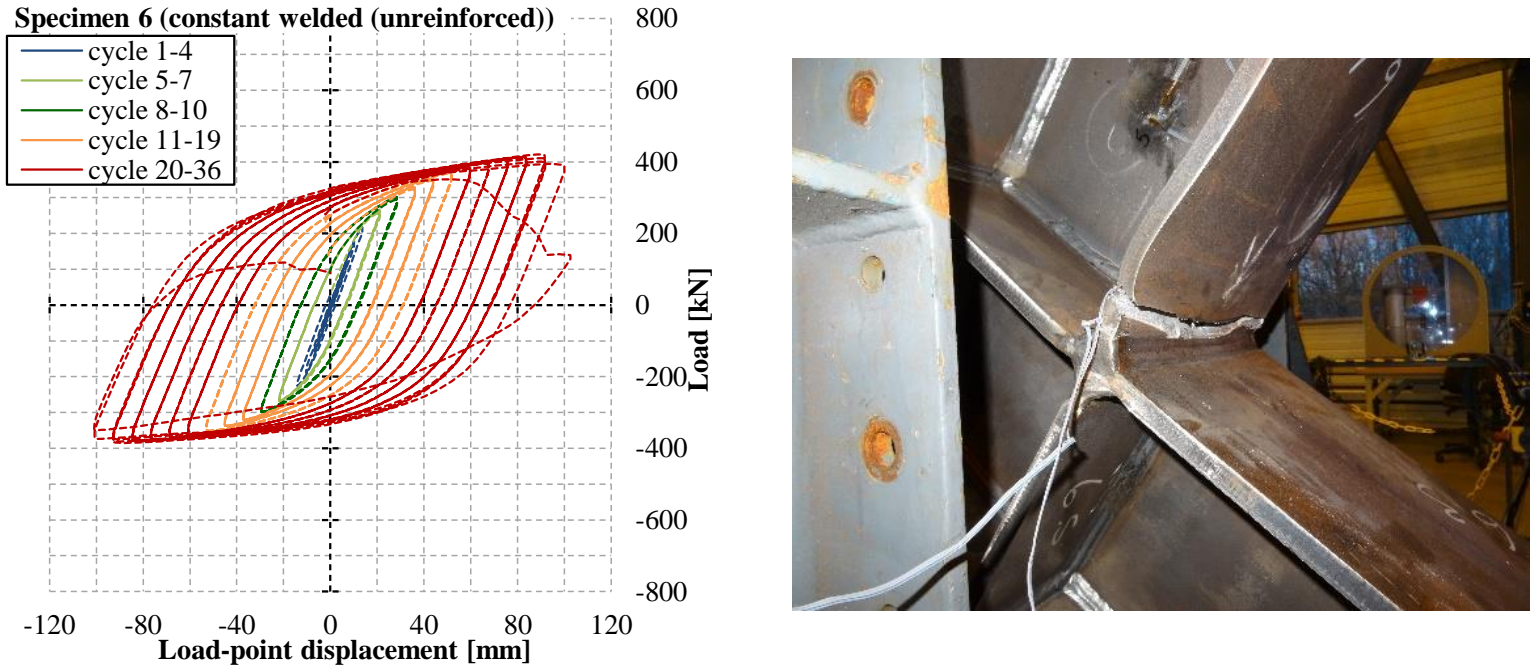

Figure 12: S6 - Cyclic load-displacement curve and failure mode 
Due to slippage in the hinges of the test setup the test specimens were loaded with slightly smaller displacements than indicated by the true movement of the jack. The measured values of displacement as well as the number of cycles until failure $N_{f}$ occurred are shown in Table 5 .

\begin{tabular}{|c|c|c|c|c|c|c|c|c|c|c|c|c|c|}
\hline \multirow{2}{*}{ Specimen } & \multicolumn{12}{|c|}{$e_{i}$ in [mm] for cycle } & \multirow{2}{*}{$\begin{array}{r}N_{f} \\
{[-]}\end{array}$} \\
\hline & 4 & $5-7$ & 8-10 & 11-13 & 14-16 & 17-19 & $20-22$ & 23-25 & $26-28$ & 29-31 & $32-34$ & $35-36$ & \\
\hline 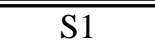 & 20.7 & 31.4 & 42.7 & 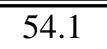 & 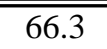 & 78.6 & 91.0 & 104.1 & - & - & 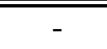 & - & 23.3 \\
\hline S2 & 20.8 & 31.9 & 43.5 & 55.1 & 67.0 & 79.6 & - & - & - & - & - & - & 18.3 \\
\hline S3 & 15.9 & 24.2 & 33.2 & 42.7 & 52.5 & 62.6 & 73.2 & 86.3 & - & - & - & - & 22.3 \\
\hline S4 & 16.1 & 24.8 & 33.8 & 43.4 & 53.1 & 63.5 & 77.2 & - & - & - & - & - & 18.3 \\
\hline S5 & 20.4 & 31.1 & 42.6 & 54.2 & 66.0 & 77.6 & 89.6 & 101.9 & - & - & - & - & 22.8 \\
\hline S6 & 13.9 & 21.4 & 28.9 & 36.7 & 44.5 & 52.3 & 60.2 & 68.1 & 76.1 & 84.0 & 92.2 & 67.4 & 35.3 \\
\hline
\end{tabular}

Table 5: Measured values of displacement and number of cycles until failure

\section{NUMERICAL SIMULATIONS OF TESTS}

\subsection{Description of numerical simulations}

Subject of these simulations was the numerical recalculation and verification of the above described tests. The geometries of the FE-models were chosen equal to the measured dimensions of the test specimens, Figure 13.

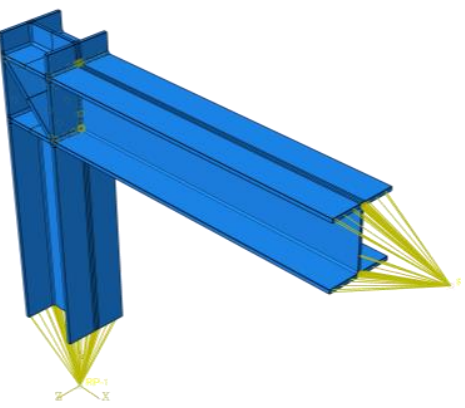

(S1)

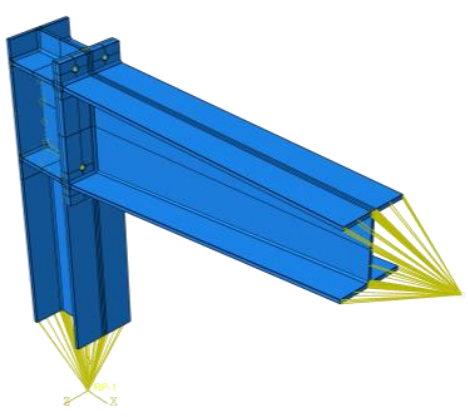

(S4)

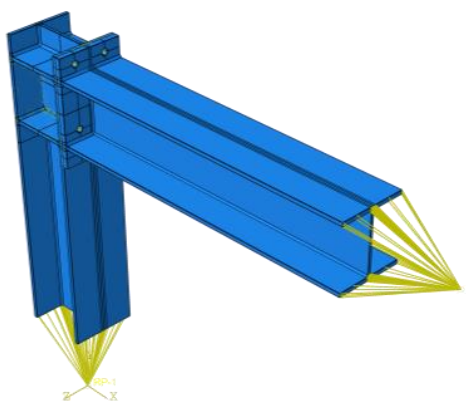

$(\mathrm{S} 2)$

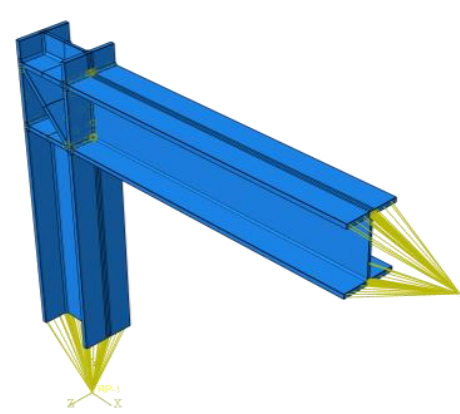

(S5)

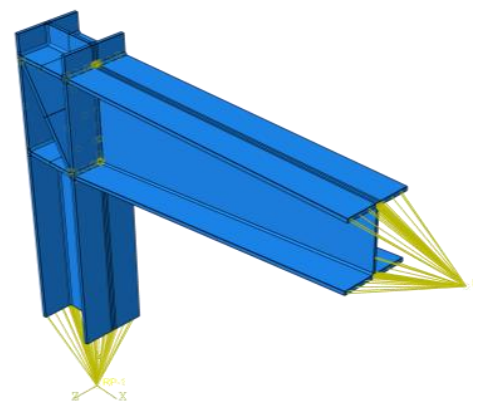

(S3)

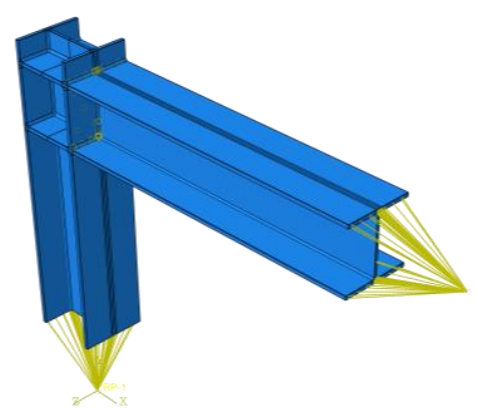

(S6)

Figure 13: Overview FE-models

The FE-program ABAQUS was used and the FE-models were created using 8-node reduced-integration solid elements (type C3D8R). Both geometric and physical non-linearities were considered and moreover the FE-mesh as well as the FE-mesh refinements around the critical points were calibrated to get stable and adequate results. 
For monotonic loading conditions, in order to determine the test procedure for cyclic loading, non-linear isotropic hardening was considered using the extrapolated true stress-strain curves shown in Figure 1, whereas for cyclic loading conditions linear isotropic and nonlinear kinematic hardening according to Lemaitre Chaboche [7] were considered. The required parameters were determined analytically and were verified using numerical simulations; they are summarized in Table 6.

\begin{tabular}{ccccc}
\hline$f_{y}$ & $C$ & $\gamma$ & $Q$ & $b$ \\
{$\left[\mathrm{~N} / \mathrm{mm}^{2}\right]$} & {$[-]$} & {$[-]$} & {$[-]$} & {$[-]$} \\
\hline 320 & 26000 & 120 & - & - \\
\hline
\end{tabular}

Table 6: Material parameter for cyclic loading conditions according to Lemaitre Chaboche [7]

The boundary conditions of the test setup were considered using 2 reference points in conjunction with "coupling" definitions at both ends of the specimens (see Figure 14). The lateral support of the frame corner was incorporated by adequate boundary conditions. The simulations were run displacement-controlled with the measured loading history of the tests.

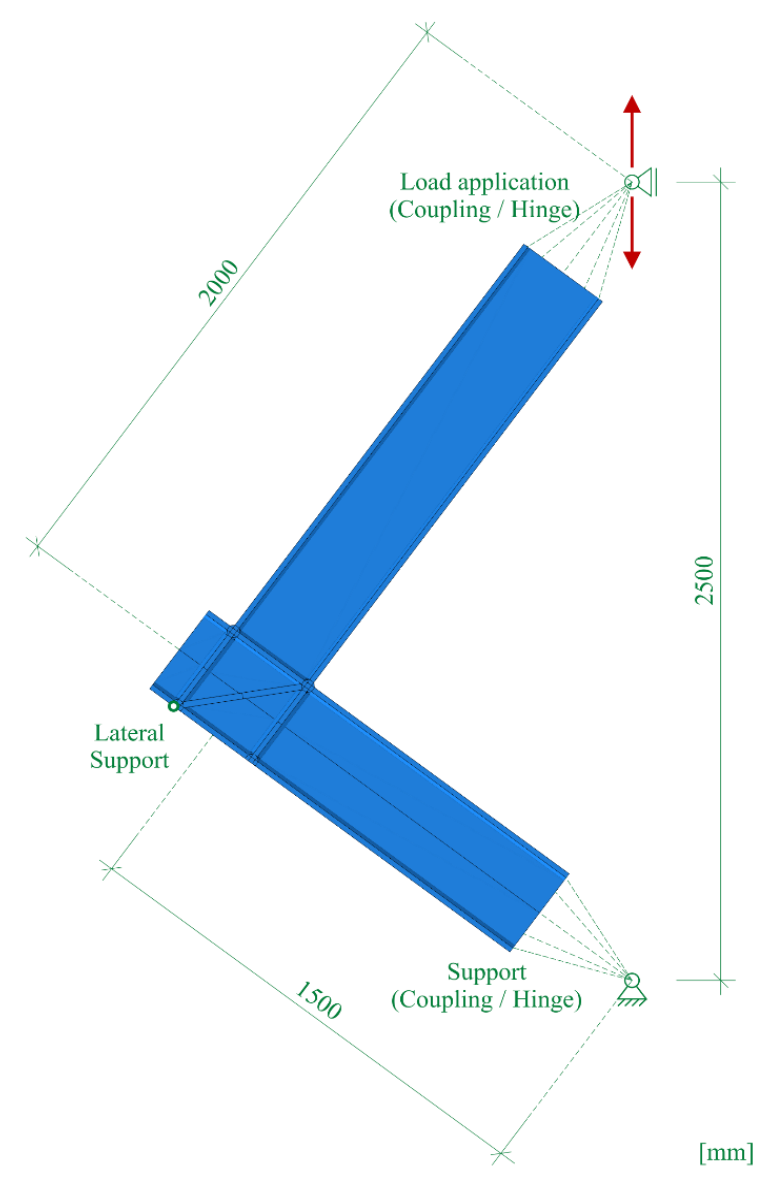

Figure 14: Load application and boundary conditions

\subsection{Numerical results for cyclic loading}

The numerical results in terms of cyclic load-displacement curves referring to the point of load application as well as deformed shapes showing the accumulated plastic strains at the end of the loading history are given in Figure 15 to Figure 20. 

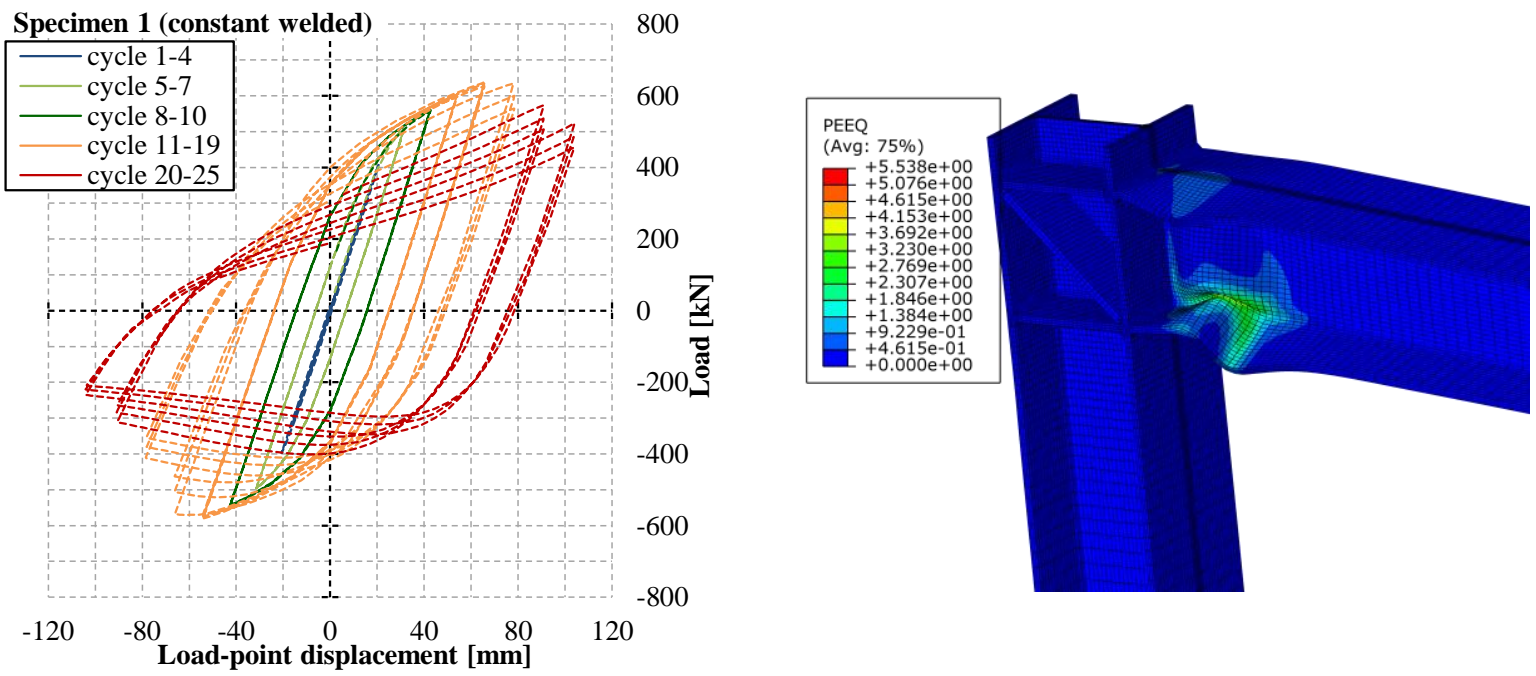

Figure 15: S1 - Cyclic load-displacement curve and failure mode
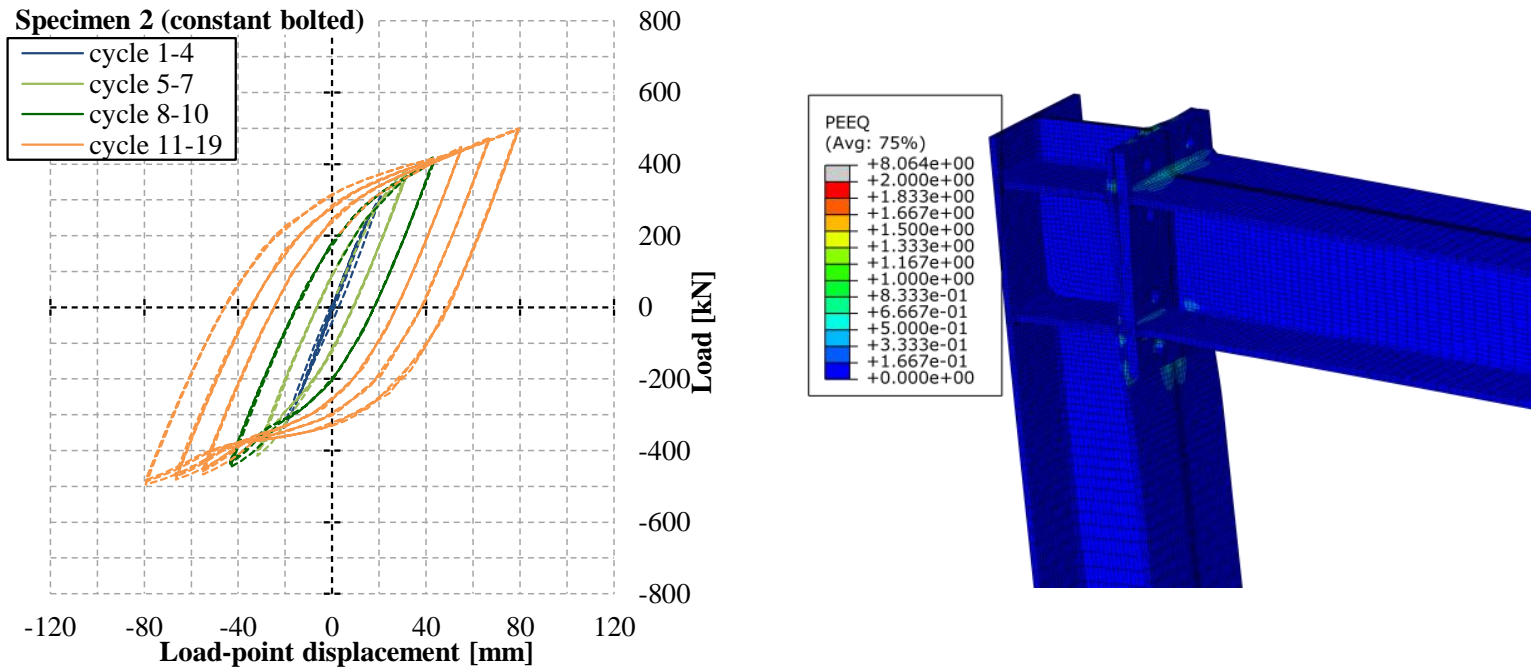

Figure 16: S2 - Cyclic load-displacement curve and failure mode
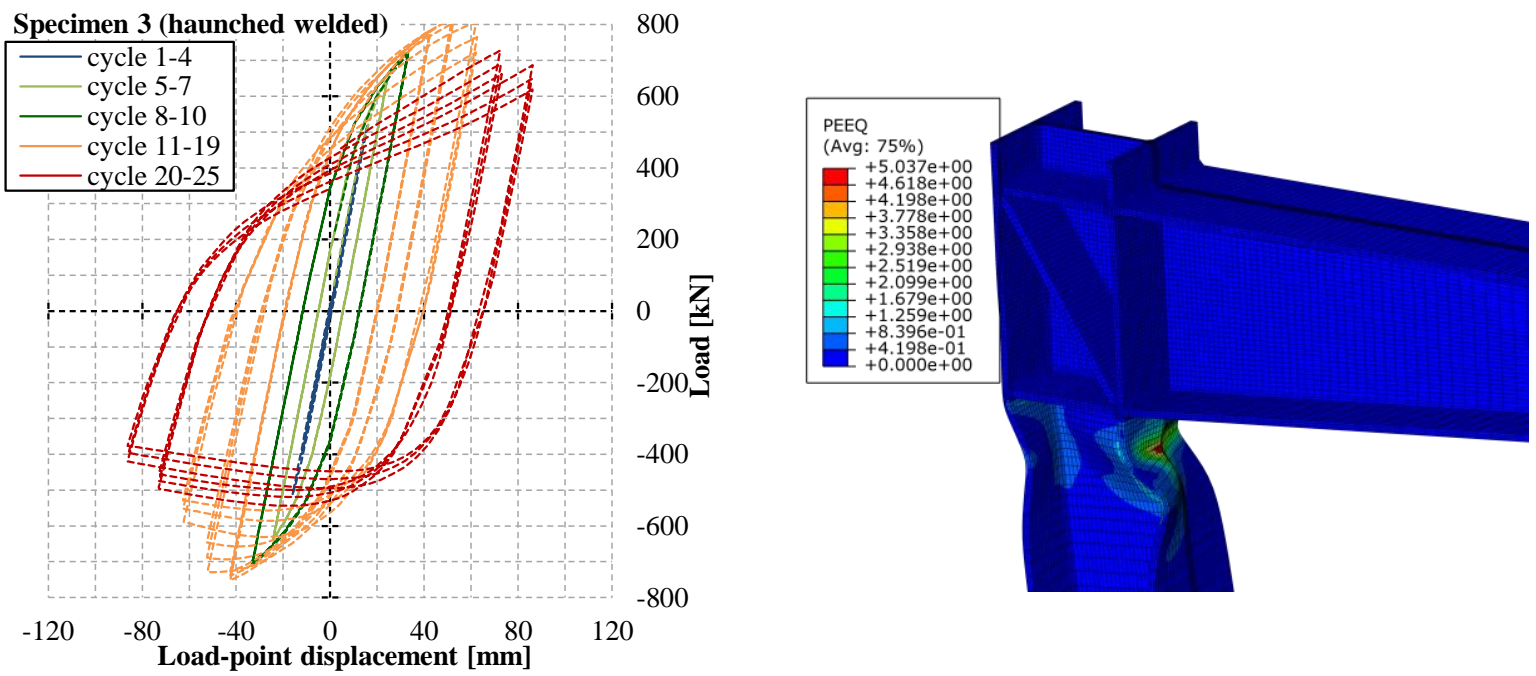

Figure 17: S3 - Cyclic load-displacement curve and failure mode 

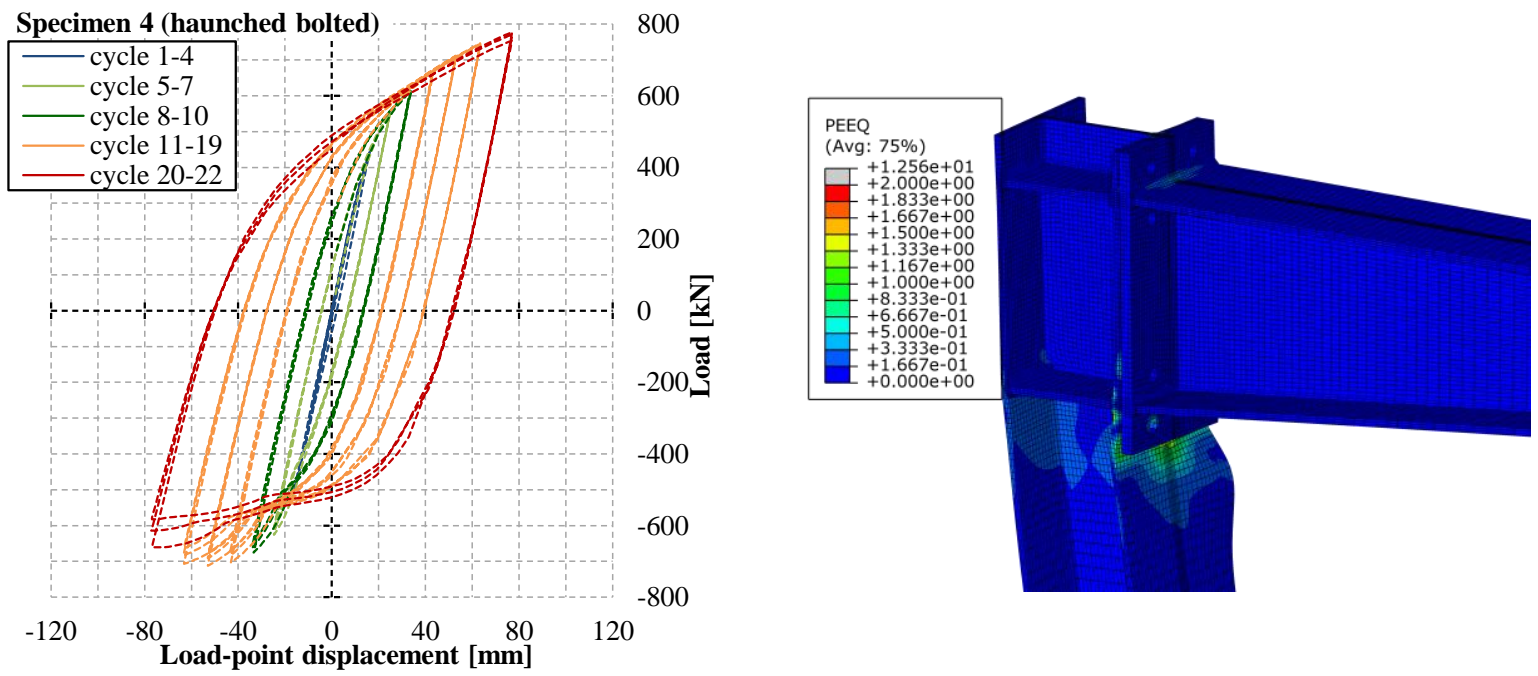

Figure 18: S4 - Cyclic load-displacement curve and failure mode

Specimen 5 (constant welded (class 1))

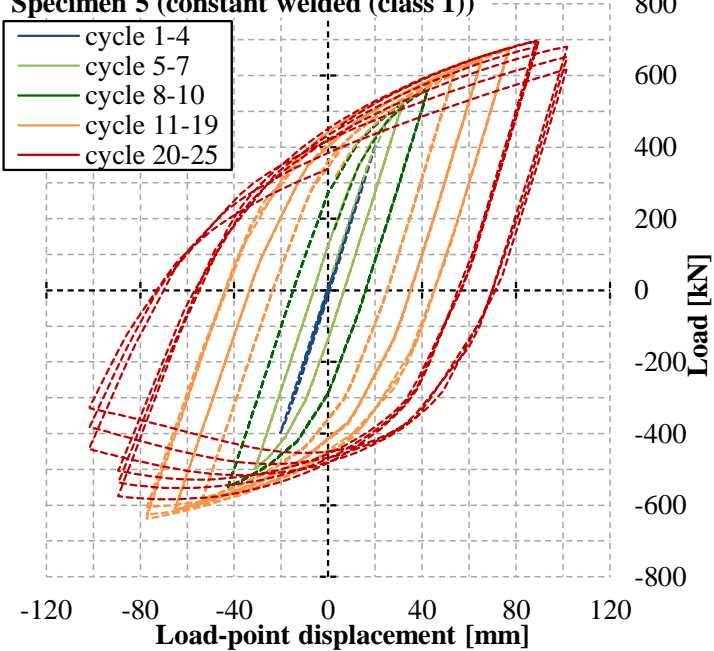

800

600

400

200
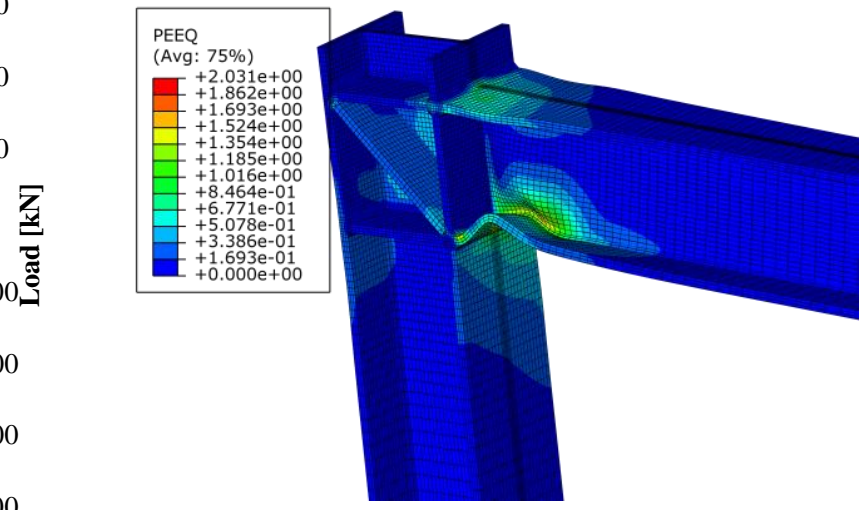

Figure 19: S5 - Cyclic load-displacement curve and failure mode
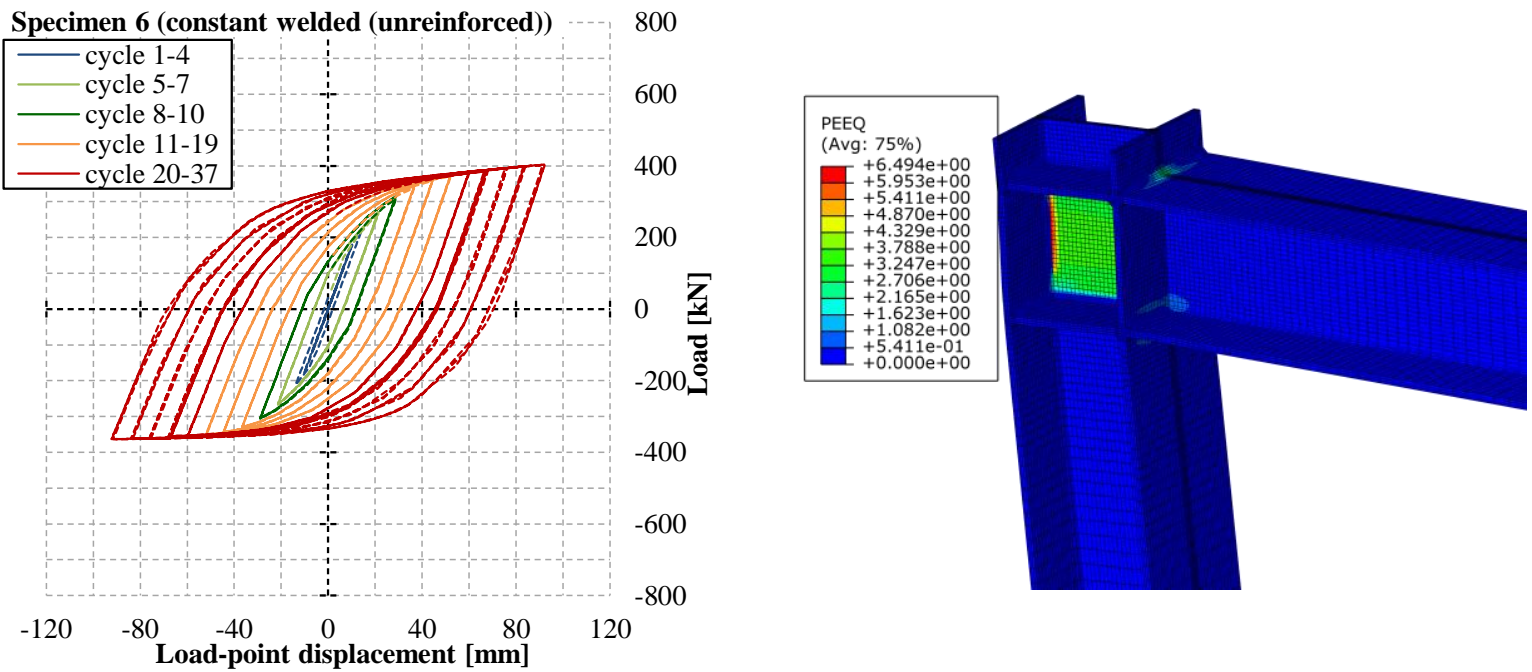

Figure 20: S6 - Cyclic load-displacement curve and failure mode 


\section{OBSERVATIONS AND CONCLUSIONS}

The numerical verification of the tests was aiming at two main aspects, the validation of the numerical model with regard to its accordance with the experimental behaviour and thus its applicability for parametric studies as well as the identification of damage and formulation of a equivalent damage criterion transferrable from damages observed in the tests to the numerical model.

The experimental and numerical load-displacement curves show a very good agreement confirming the capability of the FE-models to represent the overall performance of the investigated frame corners. For the identification of failure modes (cracks) in the numerical FEmodels an approach has been selected, in which the accumulated plastic strains $\overline{\varepsilon_{\mathrm{p}}}$ were com-

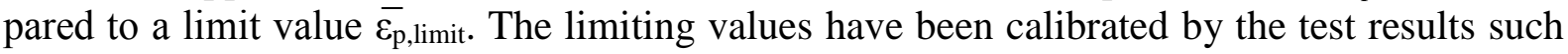
that for each tested specimen respectively its FE-models the location and the accumulated plastic strains have been determined from the simulations at the cyclic deformation stage of the tested specimen corresponding to the first visually detected crack. From this evaluation the number of cycles until failure and the location (point of failure) can be obtained.

On the basis on the findings from the tests as well as from the simulated recalculation of the tests the next step will be a parametric numerical study. The main aim of this study will be the assessment of the influences of the different components on the cyclic behaviour of MRF's as well as the development of pre-normative design rules.

\section{ACKNOWLEDGMENTS}

This work was carried out with a financial grant from the Research Fund for Coal and Steel of the European Commission, within MEAKADO project: "Design of steel and composite structures with limited ductility requirements for optimized performances in moderate earthquake areas", Grant No. RFSR-CT-2013-00022.

\section{REFERENCES}

[1] Deliverable D2.1a:" Experimental testing on class 3 and 4 steel cross-sections", RFCS project MEAKDO, Grant No. RFSR-CT-2013-00022

[2] Deliverable D2.2:" Development of numerical models of class-3 and 4 steel and composite cross-sections", RFCS project MEAKDO, Grant No. RFSR-CT-2013-00022

[3] Wieschollek, M., Hoffmeister, B. and Feldmann, M.: Experimental and numerical investigations on nozzle reinforcements, Proceedings of the ASME 2013 Pressure Vessels \& Piping Division Conference PVP2013, Paris 2013, France

[4] EN 1998 1:2010 12: "Design of structures for earthquake resistance - Part 1: General rules, seismic actions and rules for buildings", European Committee for Standardization, Brussels 2010, Belgium

[5] ECCS Recommended Testing Procedure for Assessing the Behaviour of Structural Steel Elements under Cyclic Loading, ECCS - Technical Committee 1 - Structural Safety and Loadings, Technical Working Group 1.3 - Seismic Design, Brussels 1986, Belgium

[6] Hollomon, J.H.: Tensile Deformation. Transactions of the Metallurgical Society of AIME, pp. 268-290, 1962

[7] Lemaitre, J. and Chaboche, J-L.: "Mechanics of Solid Materials", Cambridge University Press, 1990 